\title{
PHYSICO-MECHANICAL PROPERTIES OF PLYWOOD BONDED BY NANO CUPRIC OXIDE (CUO) MODIFIED PF RESINS AGAINST SUBTERRANEAN TERMITES
}

\author{
Wei Gao ${ }^{1, \wedge}$, Guanben $\mathrm{Du}^{1}$
}

\begin{abstract}
Nano $\mathrm{CuO}$ and alkane surfactant modified phenol Formaldehyde (PF) resins were applied to manufacture plywood, and physical and mechanical properties, such as shear strength, tensile property, modulus of rupture (MOR), modulus of elasticity (MOE), as well as termite resistance were evaluated. The result showed that the combination of nano $\mathrm{CuO}$ and alkane surfactantplayed different effect on tensile strength, and especially on shear strength as evaluated at different test conditions. But it was confirmed to improve the water resistance of treated plywood specimens. The introduction of nano $\mathrm{CuO}$ and surfactant did not influence the flexural properties significantly by statistically. The result of termite tests indicated that the weight loss decreases gradually from $31,12 \%$ to less than $10,37 \%$, and the mortality increases from $32,61 \%$ to higher than $86,35 \%$. And the AWPA rating also rises from 4 (very severe attack) to 7 (moderate attack).
\end{abstract}

Keywords: Mechanical properties, nano cupric oxide, phenol-formaldehyde resin, physical properties, plywood, termite resistance.

\section{INTRODUCTION}

Plywood is widely used as structural material in the manufacture of furniture, engineered flooring, housing, and other industrial products (Federation 2002, Gao and Li 2012). The plywood panels are produced by gluing several wooden plies together in layers with the perpendicular grain directions. With respect to the excellent mechanical properties obtained from the composition effect, lower-grade wood species, such as fast growing poplar, have been applied commonly to manufacture wood veneers for plywood. Generally, the fast growing wood are non or less durable wood species which are susceptible to be attacked by mould, decay fungi and termites et ac while the plywood products are used outdoors in challenging environment with high temperature and humidity. Therefore, a large number of investigations have been done to protect plywood from biological attacks (Wei-hong et al. 2005, Tascioglu and Tsunoda 2010, Tenorio et al. 2011, Terzi et al. 2011, Syofuna et al. 2012). Terzi reported that quaternary ammonia compounds and common fire retardants resulted in the improvement of termite resistance of plywood characterized by low mass losses and high termite mortalities (Terzi et al. 2011). A post-treatment by vacuum-impregnation with alkaline copper quat (ACQ) showed that ACQ did not adequately protect softwood plywood from termite, whereas the biological resistance of hardwood plywood was reasonably improved by ACQ (Tascioglu and Tsunoda 2010).

As engineered plywood were commonly glued by phenol formaldehyde resin (PF) as wood adhesive, several studies examining PF resin compatibility with preservative systems and adhesive were carried out since 1940s as systems were sought to provide durability to glue-lam products (Vick 1990, Acker and Stevens 1993ab, Prasad et al. 1994, Kartal et al. 2007). Previous treatment on veneer with either boric acid, borax, mono-ammonium phosphate (MAP), or di-ammonium phosphate (DAP) was confirmed to be effective on the termite resistance of plywood (Kartal et al. 2007). However, Vick found that the borate containing preservatives tested caused poor bonds for PF glued plywood, as did an emulsion of copper naphthenate (Vick 1990). The similar result was reported that neither CCA nor ACZA pretreatment produced negative effect on tensile strength of lap shear specimens bonded with PF resin (Prasad et al. 1994).

\footnotetext{
${ }^{1}$ College of Material Engineering, Southwest Forestry University, Kunming, Yunnan Province, P. R. 650224 China

^Corresponding author : weigaoe@gmail.com

Received: 10.12.2013 Accepted: 24.04.2014
} 
In process treatment (IPT) options, incorporating during manufacture, offered several distinct advantages on preservation of wood composites (Manning 2002). And the attempt of development of PF system with the specific function of wood preservation, as well as its application on the wood composites manufacture will be an essential approach on IPT option. However, there was no any clear and definite report on wood composites manufactured by PF resin possessing the function of wood preservation. Our previous work focused on investigating the curing kinetics and molecular structure change of this PF system (Gao 2012, Gao and Du 2013). The objective of this study was to apply nano $\mathrm{CuO}$ modified PF resins on plywood manufacturing, and specially to investigate the physical, mechanical properties and termite resistance of plywood.

\section{MATERIALS AND METHODS}

\section{Materials}

Nano copper (cupric) oxide (CuO) was obtained from Johnson Mathey Company, USA, in the form of 23-37nm particle size Aps (air plasma spray) powder with a nominal specific surface area of 25 to $40 \mathrm{~g} \mathrm{~m}^{-2}$. A kind of alkane surfactant, with compound of alkyl ether, phosphate ester and potassium salt, was prepared in the laboratory, and used in this experiment as dispersant. The aqueous PF resin was prepared in laboratory, with total sodium hydroxide of $5,20 \mathrm{wt} \%$ with $\mathrm{pH}$ value of $11 \pm 0,5$, and the molar ratio of formaldehyde to phenol was $1,8 / 1,0$. The solid content and viscosity were $48,6 \mathrm{wt} \%$, and $154 \mathrm{mPa}$.s respectively. PF resin was modified via nano $\mathrm{CuO}$ in the following procedure: the specific amount of alkane surfactant, as shown in $\mathrm{Tab}$ 1, was charged into aqueous PF resin firstly, and stirring 10min, then adding correspondence $\mathrm{CuO}$. This mixture was then allowed to stir $1 \mathrm{~h}$ at room temperature.

Table 1. The loading level of nano $\mathrm{CuO}$ and alkane surfactant based on the weight of PF resin separately.

\begin{tabular}{lcc}
\hline \multicolumn{1}{c}{ Sample } & $\begin{array}{c}\mathrm{CuO} \\
(\%)\end{array}$ & $\begin{array}{c}\text { Alkane } \\
\text { surfactant }(\%)\end{array}$ \\
\hline PF & 0 & 0 \\
Control & & 0,55 \\
PCA-1 & 0,50 & 0,55 \\
PCA-2 & 1,00 & 0,85 \\
PCA-3 & 3,00 & 1,00 \\
PCA-4 & 4,50 & \\
\hline
\end{tabular}

\section{Three layers plywood preparation and shear strength testing}

The mechanical performance of the nano $\mathrm{CuO}$ and surfactants modified $\mathrm{PF}$ resin was tested by evaluating the shear strength of thee layer plywood prepared in the laboratory utilizing the PF resin mixtures.

Three-layer plywood panels were prepared using Chinese white poplar (Populus tomentosa Carrière) veneers of $300(\mathrm{~W}) \times 300(\mathrm{~L}) \times 3,5(\mathrm{~T}) \mathrm{mm}$, obtained from a industrial plant in Hebei Province, China, and dried to approximately $3 \%$ moisture content before manufacturing. The glue spread used was a $190 \mathrm{~g} \mathrm{~m}^{-2}$ double glue line. After a $15 \mathrm{~min}$ ageing stage, the mat was pressed for $6,5 \mathrm{~min}(40 \mathrm{sec} / \mathrm{mm})$, at $160^{\circ} \mathrm{C}$ and $1,5 \mathrm{MPa}$. After hot pressing, the panels were cooled down and conditioned at $22 \pm 1^{\circ} \mathrm{C}, 65 \pm 2 \%$ relative humidity to a constant weight prior to testing. The shear strength with seven repetitions was tested according to Chinese Standard GB/T 17657-2003 (Standard 2003) for plywood. The shear strength was classified as thee types according to the sample's testing condition: $4 \mathrm{~h} 100^{\circ} \mathrm{C}$ water boiling; $24 \mathrm{~h}$ room temperature water dipping; and 5days room temperature water dipping respectively, all of which were followed by $10 \mathrm{~min}$ air-drying prior to testing. 


\section{Fifteen layers plywood preparation and testing}

Except the hot pressing period was 30min for each fifteen layers plywood, all of the veneer, glue spread, parameters of hot pressing, as well as air condition process were same to the above part of "2,2 Thee layers plywood preparation and shear strength testing". The static bending was assessed in accordance with the Chinese Standard GB/T 17657-2003 (Standard 2003). A 50mm by 370mm sample was cut from each panel and conditioned to constant weight at 20 and $65 \%$ relative humidity. The samples were placed in a universal testing machine that applied a constant center-loaded force to samples at a speed of $1 \mathrm{~mm} / \mathrm{min}$ to calculate modulus of rupture (MOR) and modulus of elasticity (MOE). The tensile strength were tested according to the Chinese Standard GB/T 17657-2003 (Standard 2003) as well.

\section{Formosan subterranean termite resistance test}

\section{Laboratory Termite Resistance Test}

Five samples with a dimension of $25 \pm 1 \times 25 \pm 1 \times 12 \pm 1 \mathrm{~mm}$ for each experiment condition and five untreated controls were taken for no-choice laboratory termite tests according to the standard of the American Wood Preservers Association (AWPA) (AWPA. 2008). Prior to each termite test, the blocks were oven-dried at $60^{\circ} \mathrm{C}$ for $72 \mathrm{~h}$ and sample weight (W1) was measured. Each test bottle $(80 \mathrm{~mm}$ diameter $\times 100 \mathrm{~mm}$ height $)$ was autoclaved for $60 \mathrm{~min}$ under $1,01 \mathrm{MPa}$ and dried. Autoclaved sand $(150 \mathrm{~g})$ and distilled water $(30 \mathrm{ml})$ were added to each bottle. Finally, four hundred termites (Coptotermes formosanus Shiraki), 360 workers and 40 soldiers, were added to the opposite sides of the test block in the container. All the containers were maintained at $24^{\circ} \mathrm{C}$. After 4 weeks, each bottle was dismantled. Live termites were counted, and test blocks were removed and cleaned. Each block was oven-dried again at $60^{\circ} \mathrm{C}$ for $72 \mathrm{~h}$ to determine the dry sample weight $\left(\mathrm{W}_{2}\right)$. From the measurements, sample weight loss $\left[\left(\mathrm{W}_{1}-\mathrm{W}_{2}\right) / \mathrm{W}_{1}\right]$ and termite mortalities were determined.

\section{Field Termite Resistance Test}

A set of 10 replicates of fifteen layer plywood specimens measuring $100 \pm 1 \times 25 \pm 1 \times 12 \pm 1 \mathrm{~mm}$ were used to field termite resistance test in Guangzhou, Guangdong Province, China, which was performed in accordance with a brick assembly technique of Field Test Procedures for Termites of AWPC protocol (Standard 2007).

The test was occurred within a 6 Litter plastic container. Test specimens were randomly arranged and alternated with highly susceptible feeder specimens (Cunninghamia lanceolata Lamb.): $25 \times 25 \times 100 \mathrm{~mm}$ ). Test specimens and feeder specimens were separated by corrugated cardboard. All containers were placed on hollow masonry bricks (100mm thick). The bricks were on timber-filled trenches, which are known to contain infestation of the target species of termite. Wooden pegs $(200 \mathrm{~mm}$ long) aid termite access though the bricks and into the containers. Each container was covered with insulating material and secured with soil. The test duration was 9 months from Sep $3^{\text {rd }} 2012$ to May $3^{\text {rd }} 2013$. For both laboratory and field termite tests, samples were rated on 0 to 10 ( 0 is completely termite damage and 10 is no termite damage) according to AWPA protocol (Standard 2007). 


\section{RESULTS AND DISCUSSION}

\section{Shear strength of three layer plywood}

Table 2. Shear strength of plywood bonded by PF resin control and PF resin modified via nano $\mathrm{CuO}$ as adhesives.

\begin{tabular}{|c|c|c|c|}
\hline \multirow[b]{2}{*}{ Sample } & \multicolumn{3}{|c|}{ Shear Strength (MPa) } \\
\hline & $\begin{array}{c}4 \text { hours } 100^{\circ} \mathrm{C} \\
\text { water }\end{array}$ & $\begin{array}{l}24 \text { hours room } \\
\text { temperature water }\end{array}$ & $\begin{array}{c}4 \text { days room } \\
\text { temperature } \\
\text { water }\end{array}$ \\
\hline $\begin{array}{c}\text { PF } \\
\text { Control }\end{array}$ & $2,86(0,30)$ a $\underline{32}$ & $3,34(0,20)$ a 28 & $2,72(0,12)$ a $\underline{31}$ \\
\hline PCA-1 & $2,64(0,23)$ a $\underline{27}$ & $2,85(0,14)$ bc $\underline{37}$ & $2,74(0,26)$ a 29 \\
\hline PCA-2 & $2,88(0,12)$ ac 32 & $2,72(0,31)$ b $\underline{25}$ & $2,87(0,19)$ a 22 \\
\hline PCA-3 & $3,03(0,31)$ bc 29 & $3,09(0,16)$ acd 21 & $2,82(0,10)$ a 33 \\
\hline PCA-4 & $2,84(0,18)$ ac 24 & $2,97(0,20)$ bd 26 & $3,19(0,20)$ b 30 \\
\hline
\end{tabular}

*Values represent means of 5 replicates per treatment, while figures in parentheses are the standard deviation. Means with a column followed by the same letter are not significantly different using Tukey's Studentized Range Test $(\alpha=0,05)$. Numbers in italics and underline front represent the wood failure of the corresponding shear strength, and the unit is percentage $(\%)$.

In order to develop much more information about shear strength of nano $\mathrm{CuO}$ modified $\mathrm{PF}$ resin, the test conditions were performed to investigate the wet shear strength (Table 2). It is surprising that after $4 \mathrm{~h}$ boiling water dipping, the shear strength of some treated samples increased than that of the PF control. Especially the result of specimen PCA-3, the shear strength increases from 2,86 to 3,03MPa, and statistical analyses using one-way analysis of variance shows that the modification of PCA-3 improved the wet shear strength significantly. This is probably due to the effect of post curing, caused by the heat energy from $100^{\circ} \mathrm{C}$ water, was superior than the attacking of water on the glueline, and adding the nano $\mathrm{CuO}$ enhanced this effect (Gao and $\mathrm{Du}$ 2013). Moreover, this effect must be related to the loading level of nano $\mathrm{CuO}$ and alkane surfactant. Because the wet shear strength of PCA-1 and 4 declined while comparing with that of PF control.

As the dipping time in water at room temperature increased from $24 \mathrm{~h}$ to 4 days, the shear strength of PF control reduced significantly from 3,34 to $2,72 \mathrm{MPa}$. However, the result of treated specimens was diversifying as shown in Table 2. The shear strength of PCA-1 and 3 were declined, while that of PCA-2 and 4 were improved. Additionally, after 4 days dipping in room temperature water, the shear strength of all treated samples were superior to that of $\mathrm{PF}$ control, which means the combination of nano $\mathrm{CuO}$ and alkane surfactant improved the water resistance of PF bonded plywood. Specifically, the addition of nano $\mathrm{CuO}(1 \%)$ alone or in combination with alkane surfactant $(0,55 \%)$ to the PF resin mixture was found to be effective in accordance with the shear strength of the plywood. These results suggest that this modification of PF resin met the important criteria for its application in the manufacture of plywood. 


\section{Tensile strength of fifteen layer plywood}

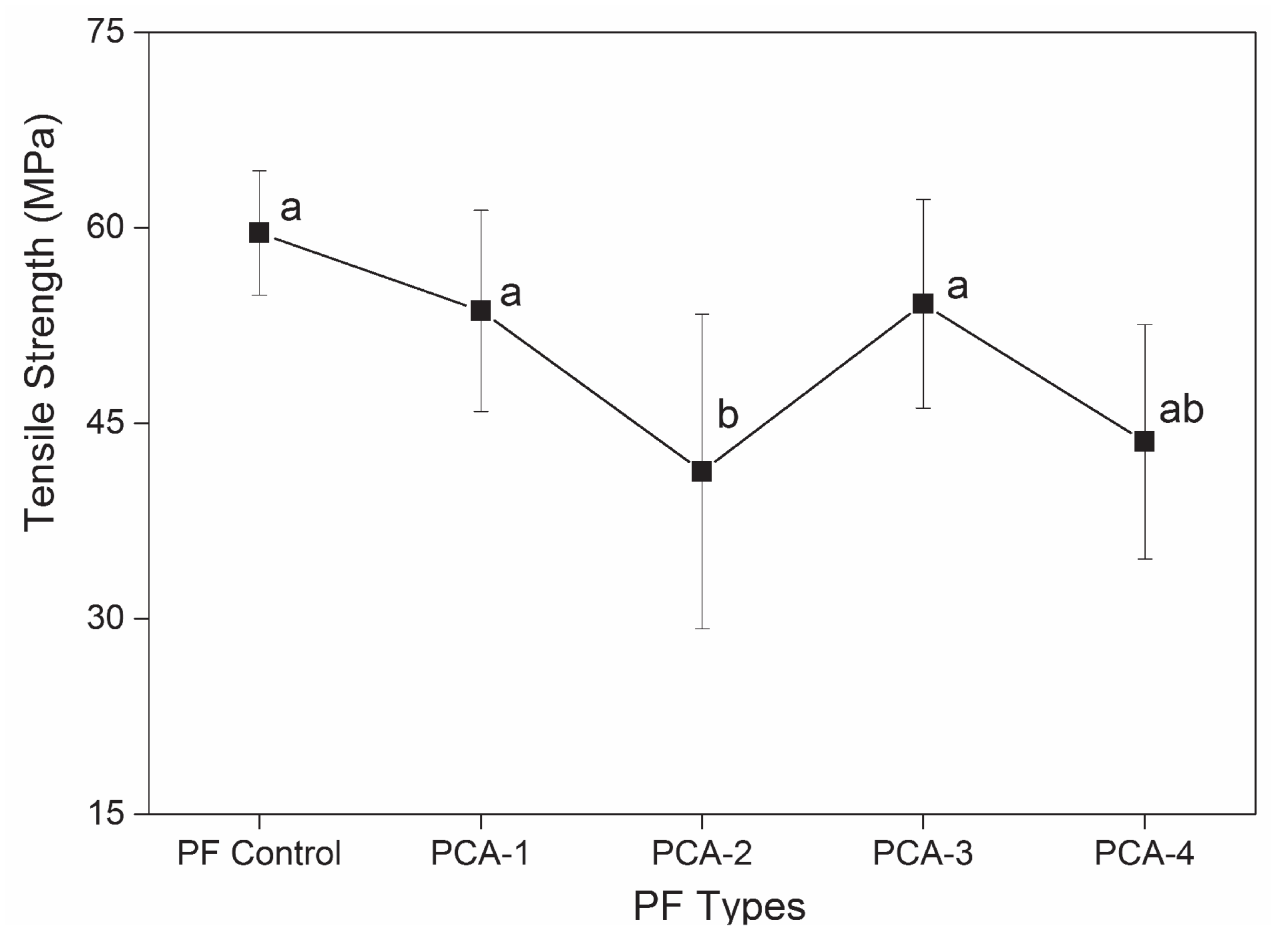

Figure 1. Tensile strength of fifteen layer plywood bonded by PF control and PF resin modified via nano $\mathrm{CuO}$ and alkane surfactant. A column labelled by the same letter are not significantly different using Tukey's Studentized Range Test $(\alpha=0,05)$.

Tensile strength (TS) of fifteen layer plywood is shown in Figure 1. The TS for control panels bonded with unmodified PF resin averaged 59,6MPa. The TS of panels decreased gradually to 41,3MPa for PCA-2 as loading level of nano $\mathrm{CuO}$ and alkane surfactant reached to $1,00 \%$ and $0,55 \%$, respectively (Table1). Then it climbed again to $54,16 \mathrm{MPa}$ of PCA-3. The general decrease in TS with increasing the application rates of nano $\mathrm{CuO}$ and alkane surfactant have a deleterious effect on the tensile property.

Except PCA-2 and PCA-4, there was a non significant difference between the TS of panels made with both PF control and modified PF resin. Board labeled PCA-3 also had higher TS values, but not significantly different from others. This suggests that if nano $\mathrm{CuO}$ and alkane surfactant are to be considered, the most favorable application rate for optimal TS would be 3,00\% nano $\mathrm{CuO}$ and $0,85 \%$ alkane surfactant modified $\mathrm{PF}$ resin. 


\section{Bending properties of fifteen layer plywood}

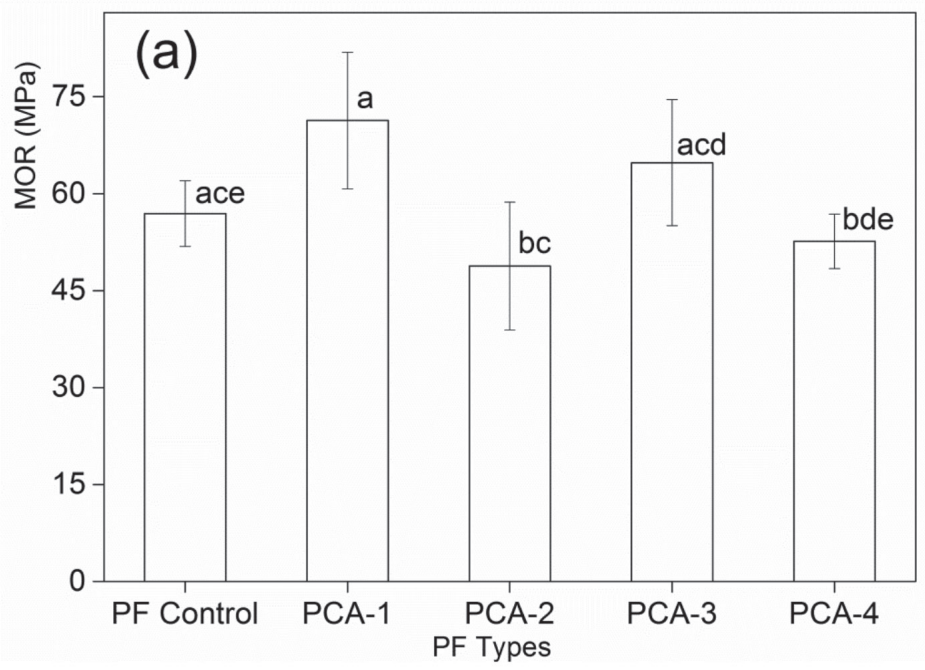

Figure 2. Flexural strength of Modulus of Elasticity (MOE) (a) and Modulus of Rupture (MOR) (b) of fifteen layer plywood. A column labelled by the same letter are not significantly different using Tukey's Studentized Range Test $(\alpha=0,05)$.

The flexural properties, shown in figure 2, were separated into Modulus of Elasticity (MOE) and Modulus of Rupture (MOR) respectively. Comparing with the result of tensile strength (Figure 1), nano $\mathrm{CuO}$ and alkane surfactant performed different effect on flexural properties of fifteen layers plywood. The highest MOR (MPa) and MOE (GPa) values were obtained from the panels labelled as PCA-1. Only PCA-2 and PCA-4 got the lower flexural strength than that of PF Control, but the results were not significantly statistically different, which suggested that the introduction of nano $\mathrm{CuO}$ and surfactant did not influence the flexural properties significantly. Panel labelled as PCA-3 had slightly higher MOR (MPa) and MOE (GPa) values than that of PF Control (MPa, and GPa) although they were not significantly different in statistically, which confirmed the above conclusion that the most favorable application rate of nano $\mathrm{CuO}$ and alkane surfactant for $\mathrm{PF}$ resin modification would be $3,00 \%$ and $0,85 \%$ respectively. 


\section{Termite resistance of fifteen layers plywood}

Table 3. Laboratory termite resistance test results of AWPA rating, weight losses and termite mortality of fifteen layer plywood glued by nano $\mathrm{CuO}$ modified PFresin in accordance with AWPA E1-06 test.

\begin{tabular}{|c|c|c|c|}
\hline $\begin{array}{l}\text { Plywood sample } \\
\text { group }\end{array}$ & $\begin{array}{l}\text { Mean weight } \\
\operatorname{loss}^{1}(\%)\end{array}$ & $\begin{array}{c}\text { Mean } \\
\text { mortality }^{1}(\%)\end{array}$ & $\begin{array}{l}\text { Mean } \\
\text { AWPA } \\
\text { rating }^{2}\end{array}$ \\
\hline PF Control & $31,12(4,71) a$ & $32,61(9,65) \mathrm{a}$ & 4,18 \\
\hline PCA-1 & $30,13(3,69) \mathrm{a}$ & $43,27(4,51) \mathrm{b}$ & 4,69 \\
\hline PCA-2 & $21,49(6,76) b c$ & $67,59(3,29) b c$ & 5,13 \\
\hline PCA-3 & $15,59(1,69) \mathrm{cd}$ & $74,86(4,07) \mathrm{c}$ & 6,47 \\
\hline PCA-4 & $10,37(1,51) \mathrm{d}$ & $86,35(5,12) \mathrm{d}$ & 7,11 \\
\hline $\begin{array}{c}\text { Reference: Chinese fir } \\
\text { (Cunninghamia } \\
\text { lanceolata) }\end{array}$ & $31,60(0,13) \mathrm{a}$ & $39,74(1,61) \mathrm{ac}$ & 4,05 \\
\hline
\end{tabular}

The results of laboratory no-choice termite tests are shown in table 3. It indicated that nano $\mathrm{CuO}$ has a positive effect on improving termite resistance of fifteen layers plywood. After 4 weeks' tests, the weight loss and termite mortality was respectively $31,12 \%$ and $32,61 \%$ for plywood bonded by PF control, while the mortality value is consistent to the reported results as well by Lee et al. (2004) and 13,0\% by Smart and Wall (2006). After introducing nano $\mathrm{CuO}$ via alkane surfactant, the weight loss decreases gradually from $31,12 \%$ to less than $10,37 \%$, and the mortality increases from $32,61 \%$ to higher than $86,35 \%$. The AWPA rating also rises from 4 (very severe attack) to 7 (moderate attack).

Table 4. Field termite resistance test results in accordance with AWPC protocols, weight losses and AWPA ratings of fifteen layer plywood glued by nano $\mathrm{CuO}$ modified $\mathrm{PF}$ resin.

\begin{tabular}{ccc}
\hline $\begin{array}{c}\text { Plywood sample } \\
\text { group }\end{array}$ & $\begin{array}{c}\text { Mean weight } \\
\text { loss }^{1}(\%)\end{array}$ & $\begin{array}{c}\text { Mean } \\
\text { AWPA } \\
\text { rating }^{2}\end{array}$ \\
\hline PF Control & $11,79(3,90) \mathrm{a}$ & 4,17 \\
PCA-1 & $10,24(1,95) \mathrm{a}$ & 6,67 \\
PCA-2 & $9,33(3,17) \mathrm{bc}$ & 6,78 \\
PCA-3 & $8,26(3,84) \mathrm{cd}$ & 6,92 \\
PCA-4 & $8,17(2,62) \mathrm{d}$ & 7,01 \\
$\begin{array}{c}\text { Reference: Chinese } \\
\text { red pine (Pinus } \\
\text { tabuliformis) }\end{array}$ & $68,72(5,78) \mathrm{e}$ & 1,33 \\
\hline
\end{tabular}

${ }^{1}$ Weight loss are the average value of 12 samples from field test, and numbers in parentheses are the standard deviations. A column labelled by the same letter are not significantly different using Tukey's Studentized Range Test $(\alpha=0,05)$.

2 AWPA E1-06 visual rating scale of 10 (sound), 9 (slight attack), 7 (moderate attack, penetration), 4 (very severe attack), 0 (failure).

The weight loss and visual rating scale of plywood samples after being exposed in the field termite test is listed in table 4. After 9 months of above ground exposure in Guangzhou, Guangdong Province, where Coptotermes formosanus Shiraki are present, termite activity was evidenced by a rating of 8 on samples made with nano $\mathrm{CuO}$ and alkane surfactant modified $\mathrm{PF}$ resin. Only termite activity was evaluated, no attention was given to decay or other destructive biological degradation. 

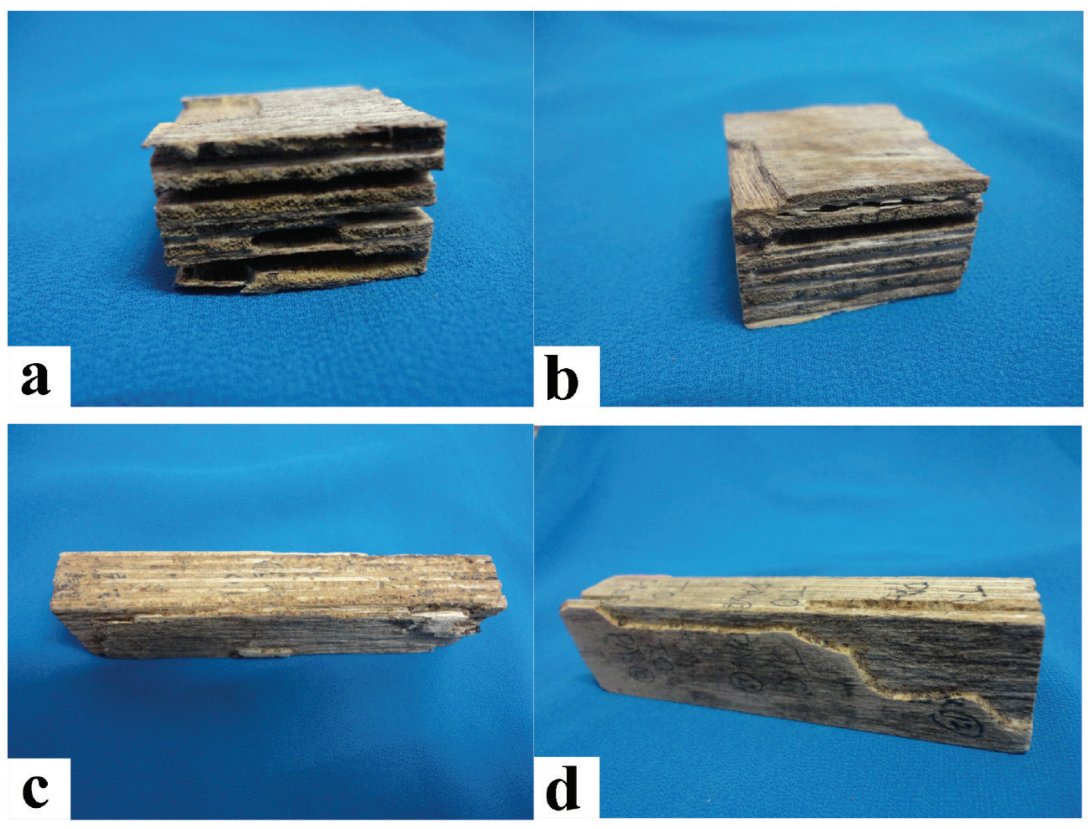

Figure 3. Fifteen layer plywood after cleaning at the end of the both laboratory and field termite resistance test. Control sample after laboratory test (a), PCA-3 after laboratory test (b), control sample after field test (c), PCA-3 after field test (d).

The typical selected samples after termite test shown in figure 3 provide some important information that the most termite attack happened on the inner sites of cross section for laboratory test, and the both surface layers for field test. This is completely different with the termite test result of wood timber or oriented strand board that both cross section and surface layer were destroyed. It must be related to the essential of glue line treatment for plywood that it is extremely hard to penetrate ingredients of preservatives into wood matrix, and the surface of unprotected wood was exposed. Thus, it is necessary to provide additional preservation for glueline treated plywood as well as laminated veneer board, especially for the cross section and surface layers. 


\section{CONCLUSIONS}

The combination of nano $\mathrm{CuO}$ and alkane surfactant, performing deleterious effect on the tensile property of PF bonded plywood, played different effect on shear strength as evaluated at different test conditions. But it was confirmed that the modification improved the water resistance of treated specimens. The introduction of nano $\mathrm{CuO}$ and surfactant did not influence the flexural properties significantly, and the MOR and MOE values of PCA-3 were slightly higher than that of PF Control. After laboratory no-choice termite tests, the weight loss decreases gradually from $31,12 \%$ to less than $10,37 \%$, and the mortality increases from $32,61 \%$ to higher than $86,35 \%$. And the AWPA rating also rises from 4 (very severe attack) to 7 (moderate attack). The future work should be focused on the improvement of termite resistance by increasing the loading level of nano $\mathrm{CuO}$ or other preservatives, while the physic-mechanical properties must be guaranteed.

\section{ACKNOWLEDGEMENTS}

The authors express their gratitude to the National Natural Science Foundation of China (granted 31100423), and the Key Project of Chinese Ministry of Education (granted 212163) for financial support. Authors also wish to thank China Scholarship Council for the financial support to Dr. Wei Gao, Associate professor, visit to Michigan State University, USA from Aug 2013 to Aug 2014.

\section{REFERENCES}

Acker, J.C.V.; Stevens, M.K. 1993a. Improvement in decay resistance of some commercial plywoods by waterborne and solvent-borne preservative treatments. (IUFRO) Symposium on the Protection of WoodBased Composites, Madison, WI, Forest Products Society.

Acker, J.C.V.; Stevens, M.K. 1993b. Variation in the decay resistance and treatability of plywood. (IUFRO) Symposium on the Protection of Wood-Based Composites, Madison, WI, Forest Products Society.

Federation, F.F.I. 2002. Handbook of Finnish plywood. Kirjapaino Markprint Oy, Lahti, Finland.

Gao, W. 2012. ${ }^{13} \mathrm{C} \mathrm{CP} / \mathrm{MAS}$ NMR analysis of cure characteristics of phenol formaldehyde resin in the presence of wood composite preservatives and wood: effect of ammonium pentaborate and copper compounds. Iranian Polymer Journal 21(5): 283-288.

Gao, W.; Du, G. 2013. Curing kinetics of nano cupric oxide $(\mathrm{CuO})$ modified PF resin as wood adhesive: Effect of surfactant. Journal of Adhesion Science and Technology 27(22): 2421-2432.

Gao, W.; Li, J. 2012. Influence of uron resins on the performance of UF resins as adhesives for plywood. Maderas. Ciencia y tecnología 14(1): 3-12.

GB/T 17657-2003. 2003. Tests methods of evaluating the properties of wood-based panels and surface decorated wood-based panels. China, National Technology Surveillance Bureau, pp 25-30.

Lee, S.; Wu, Q.; Smith, W.R. 2004. Formosan subterranean termite resistance of borate-modified strandboard manufactured from southern wood species: A laboratory trial. Wood and Fiber Science 36(1): 107-118. 
Manning, M.J. 2002. Wood protection processes for engineered wood products. Enhancing the Durability of Lumber and Engineered Wood Products. FPS Symposium Proceedings, Madison, WI., Forest Products Society.

Kartal, S.N; Ayrilmis, N.; Imamura, Y. 2007. Decay and termite resistance of plywood treated with various fire retardants. Building and Environment 42(3): 1207-1211.

Prasad, T.R.N.; Humphey, P.E.; Morrell, J.J. 1994. The effects of chomated copper arsenate and ammoniacal copper zinc arsenate on shear strength development of phenolic resin to Sitka spruce bonds. Wood and Fiber Science 26(2): 223-228.

Smart, R.; Wall, W. 2006. Copper borate for the protection of engineered wood composites. International Research Group on Wood Preservation, Tromsø, Norway.

Standard, A. 2007. Protocols for assessment of wood preservatives. Ensis-Clayton, Australasian Wood Preservation Committee.

Syofuna, A.; Banana, A.Y.; Nakabonge, G. 2012. Efficiency of natural wood extractives as wood preservatives against termite attack. Maderas. Ciencia y tecnología 14(2): 155-163.

Tascioglu, C.; Tsunoda, K. 2010. Laboratory evaluation of wood-based composites treated with alkaline copper quat against fungal and termite attacks. International Biodeterioration \& Biodegradation 64(8): 683-687.

Tenorio, C.; Moya, R.; Muñoz, F. 2011. Comparative study on physical and mechanical properties of laminated veneer lumber and plywood panels made of wood from fast-growing Gmelina arborea trees. Journal of Wood Science 57(2): 134-139.

Terzi, E.; Kartal, S.N.; White, R.; Shinoda, K.; Imamura, Y. 2011. Fire performance and decay resistance of solid wood and plywood treated with quaternary ammonia compounds and common fire retardants. European Journal of Wood and Wood Products 69(1): 41-51.

Vick, C.B. 1990. Adhesion of phenol-formaldehyde resin to waterborne emulsion preservatives in aspen veneer. Forest Products Journal 40(11-12): 25-30.

Wei-hong, W.; Kent, S.; Freitag, C.; Leichti, R.; Morrell, J. 2005. Effect of moisture and fungal exposure on the mechanical properties of hem-fir plywood. Journal of Forestry Research 16(4): 299-300. 